\title{
A Review of Four Practice Guidelines of Inflammatory Bowel Disease
}

Okelue E. Okobi ${ }^{1}$, Iboro O. Udoete ${ }^{2}$, Oyinlola O. Fasehun ${ }^{3}$, Tobechukwu Okobi ${ }^{4}$, Endurance O. Evbayekha $^{5}$, Joanna J. Ekabua ${ }^{6}$, Henry Elukeme ${ }^{7}$, Imoh L. Ebong ${ }^{8}$, Olamide O. Ajayi ${ }^{9}$, Iyanu V. Olateju ${ }^{10}$ , Anthonette Taiwo ${ }^{11}$, Ifeoma C. Anaya ${ }^{12}$, Janet A. Omole ${ }^{13}$, Mireille B. Nkongho ${ }^{14}$, Ugochi Ojinnaka ${ }^{15}$, Abimbola O. Ajibowo ${ }^{16}$, Omosefe E. Ogbeifun ${ }^{17}$, Osemwegie O. Ugbo ${ }^{18}$, Ovie Okorare ${ }^{19}$, Zainab Akinsola $^{20}$, Rahman A. Olusoji ${ }^{21}$, Ijeoma O. Amanze ${ }^{22}$, Jane N. Nwafor ${ }^{23}$, Nnenna A. Ukoha ${ }^{24}$, Thomas A. Elimihele 25

1. Family Medicine, Lakeside Medical Center, Belle Glade, USA 2. Public Health, Central Michigan University, Mount Pleasant, USA 3. Internal Medicine, University College Hospital, Ibadan, NGA 4. Internal Medicine, Bronx Care Health System, New York, USA 5. Isolation/Internal Medicine, Stella Obasanjo Isolation Center, Benin, NGA 6. Infectious Disease, University of Louisville, Louisville, USA 7. Internal Medicine, Floyd Medical Center, Rome, USA 8. Internal Medicine, University of Ghana School of Medicine and Dentistry, Accra, GHA 9. Internal Medicine, Obafemi Awolowo College of Health Sciences, Olabisi Onabanjo University, Sagamu, NGA 10. Internal Medicine, Washington Adventist University, Takoma Park, USA 11. Internal Medicine/Health Information Management, Betsy Johnson Hospital, Dunn, USA 12. Pathology and Laboratory Medicine, Ahmadu Bello University, Zaria, NGA 13. Internal Medicine, California Institute of Behavioral Neurosciences and Psychology, Fairfield, USA 14. Psychiatry, Saint James School of Medicine, Saint Vincent, VCT 15. Family Medicine, Lankenau Medical Center, Wynnewood, USA 16. Internal Medicine, Lugansk Medical University, Lugansk, UKR 17. Public Health, University of West Florida, Florida, USA 18. Oncology Research, Baylor Scott \& White Health, Dallas, USA 19. Internal Medicine, Delta State University, Abraka, NGA 20. Internal Medicine, Windsor University School of Medicine, Toronto, CAN 21. Internal Medicine, St. Helens and Knowsley Teaching Hospitals National Health Service, Prescot, GBR 22. Internal Medicine, Molly Specialist Hospital, Ibadan, NGA 23. Internal Medicine, University of the District of Columbia, Silver Spring, USA 24. Internal Medicine, Royal Cross Methodist Hospital, Abia, NGA 25. Clinical Research, Norris Comprehensive Cancer Center, University of Southern California, Los Angeles, USA

Corresponding author: Okelue E. Okobi, drokelue.e.okobi@gmail.com

Review began 07/01/2021 Review ended 07/27/2021 Published 08/03/2021

\section{(c) Copyright 2021}

Okobi et al. This is an open access article distributed under the terms of the Creative Commons Attribution License CC-BY 4.0., which permits unrestricted use, distribution, and reproduction in any medium, provided the original author and source are credited.

\begin{abstract}
Inflammatory bowel disease (IBD) is a term that encompasses conditions characterized by chronic inflammation of the gastrointestinal tract (GIT). It includes Crohn's disease and ulcerative colitis. Major scientific organizations interested in gastrointestinal systems or GIT-focused organizations worldwide release guidelines for diagnosing, classifying, managing, and treating IBD. However, there are subtle differences among each of these guidelines. This review evaluates four evidence-based guidelines in the management of IBD and seeks to highlight the differences and similarities between them. The main differences in the evaluated guidelines were in diagnosis and treatment recommendations. The diagnosing recommendations were comparable amongst the four guidelines; however, some were more specific about limiting the number of interventions necessary to confirm a diagnosis. Regarding treatment options, each guideline had clear suggestions about what was considered ideal. Although the treatment options were identical, the main differences existed in the recommended diets and initial therapy in patients with moderate disease. Clinical practice guidelines (CPGs) recommend evidence-based practice from opinion leaders in clinical decision-making. Rather than dictating a one-size-fits-all approach in IBD management, reviewing various guidelines can enhance the cross-pollination of ideas amongst clinicians to improve decision-making. Clearly describing and appraising evidence-based reasoning for scientific recommendations remain driving factors for quality patient care. The effectiveness of CPGs in improving health and the complexities of their formation requires constant review to maximize constructive criticisms and explore possible improvements.
\end{abstract}

Categories: Family/General Practice, Internal Medicine, Gastroenterology

Keywords: ulcerative colitis (uc), guideline, treatment choices, inflammatory bowel disease, crohn's disease

\section{Introduction And Background}

Inflammatory bowel disease (IBD) is a broad term that includes chronic remittent inflammatory conditions of the gastrointestinal tract - Crohn's disease (CD) and ulcerative colitis (UC). They are both clinically diverse, each having a unique outcome, pattern of disease behavior, and location. CD characteristically causes transmural inflammation that can affect any part of the digestive tract from the mouth to the anus. At the same time, UC is typically limited to the mucosa of the colon. Pathophysiology theories of IBD have evolved over the years with multifactorial etiology, such as genetics, microbiota changes, environmental factors (like cigarette smoking), and immunological factors.

Generally, the Montreal classification adopts the clinical characterization of IBD [1]. Although reliable, there are limitations in terms of predicting the clinical course of the disease and prognosis. It is essential to 
predict the probable clinical course accurately. This stratifies patients based on their disease prognosis, enables the selection of more optimal treatments, and reduces the risk of adverse events. Major gastrointestinal organizations worldwide release guidelines for the diagnosis, classification, management, and treatment of IBD; however, there are subtle differences between each of these guidelines. This review focused on highlighting set strengths and divergences in these guidelines to illustrate the best possible management for IBD patients.

\section{Review \\ Objective}

This commentary aims to review four practice guidelines on inflammatory bowel disease (IBD) and highlight significant similarities and dissimilarities to improve the evidence-based management approach to IBD.

\section{Methodology}

We searched PubMed utilizing the keywords: "inflammatory bowel disease," "IBD," "guidelines," "treatment plan," and "diagnosis" in all possible combinations. Four guidelines were identified and used for this review because of their high level of evidence and trusted sources: British Society of Gastroenterology (BSG) consensus guidelines on managing inflammatory bowel disease in adults [2], Canadian Association of Gastroenterology (CAG) Clinical Practice Guideline for the management of inflammatory bowel disease [3], World Gastroenterology Organization (WGO) Global Guidelines on inflammatory bowel disease [4], and American Gastroenterology Association (AGA) clinical practice guideline for the management of inflammatory bowel disease [5]. We extracted information regarding diagnosis, management, and treatment and compared these findings among guidelines reporting the main differences in this review.

\section{Definition and epidemiology}

IBD is a broad term that includes conditions characterized by chronic inflammation of the gastrointestinal tract. IBD includes CD and UC [6]. According to the Centers for Disease Control and Prevention, an estimated $1.3 \%$ of United States (US) adults have been diagnosed with IBD in both variants [7]. Reports also showed an increase in incidence from $0.9 \%$ in 1999 to $1.3 \%$ in 2015 [7-8] and as many as 70,000 diagnosed each year [9].

The prevalence of CD appears to be higher in urban areas than in rural areas and increased in higher socioeconomic classes [4]. If individuals migrate to developed countries before adolescence, those initially belonging to low-incidence populations show a higher incidence of IBD. This is particularly true for the first generation of these families born in a country with a high incidence. In the past 20 years, CD has generally overtaken UC in incidence rates. In developing countries where IBD is emerging, UC is typically more common than $\mathrm{CD}$.

CD characteristically causes transmural inflammation that can affect any part of the digestive tract (from mouth to anus) in a non-continuous pattern. CD can cause complications, such as abscesses, fistulas, and strictures. UC typically only affects the mucosa of the colon. It can extend from the rectum in a proximal and continuous pattern to involve other parts of the colon. Systemic symptoms, such as inflammation of the joints, eyes, and skin, can precede the development of intestinal symptoms [10]. IBD arises in early adulthood but could also start from early childhood. The intestinal manifestations include diarrhea, abdominal pain, and perianal bleeding [11].

\section{Pathophysiology}

The pathophysiologic theories of IBD have evolved over the years, with emerging research and technological advancements [12].

\section{Genetics}

In recent studies, genetics have been found to play a more significant role in the development of IBD [13]. A little over 160 gene loci have been identified by internationally collaborative studies associated with CD and are believed to interact closely with environmental and microbial factors.

\section{Environment}

Environmental factors, such as smoking, diet consumption, physiological stress, psychological elements, and geography, are considered culprits for IBD. However, smoking has been established to have an inverse association with UC, while it conversely poses a higher risk with CD [14]. Also, vitamin D deficiency has been associated with a higher risk of IBD [15]. Drugs, such as aspirin and nonsteroidal anti-inflammatory drugs, affect the mucosa of the gastrointestinal tract and represent a higher risk for both CD and UC. Antibiotics also act to increase the risk of IBD through their effect on the microbiome.

\section{Microbial factors}


Compared to the defined healthy population, the microbiomes of CD and UC patients deviate from the healthy group, especially in individuals with surgical resection [16]. Studies have compared the microbiome of stool present in inflamed and non-inflamed segments of the intestines. Findings show reduced biodiversity in inflamed areas compared to healthy segments [11]. Recent studies, including studies by Zheng et. al., documented new potential treatment targets based on the findings on the microbiome [17$18]$.

\section{Immunological factors}

IBD is secondary to the dysfunction of innate and adaptive immune pathways, which causes an aberrant intestinal inflammatory response in patients with IBD [16].

\section{Nutrition}

Some frequently used food components and condiments impact the quality of the intestinal structure and could actuate changes in the intestinal flora, resulting in a pro-inflammatory state favorable for the development of IBD. Foods high in fatty acids and excessive protein intake have been linked to an increased risk of developing IBD. In contrast, increased dietary fiber intake was associated with a decreased risk of developing CD only [19].

\section{Diagnosis}

Clinical symptoms, such as weakness, fatigue, long-term diarrhea with abdominal pain, weight variations, and rectal bleeding, may suggest IBD. Diagnostic tests for CD and UC include physical examinations, laboratory tests, and endoscopy [20]. The BSG guidelines recommend ileocolonoscopy, including segmental colonic and ileal biopsies, for IBD disease diagnosis [2]. It is essential to consider that accessing the terminal ileum may not be possible, and small bowel disease could be hard to diagnose through this method. Therefore, if small bowel disease is suspected, a CT enterography following the ileocolonoscopy is recommended. The BSG guidelines also suggest that patients do not require routine upper gastrointestinal endoscopy as part of the diagnosis unless upper gastrointestinal symptoms are present. Where ulcerative colitis is diagnosed by sigmoidoscopy, they recommended a full ileocolonoscopy to delineate disease extent, the severity of inflammation, and to exclude Crohn's disease (Grade: strong recommendation, very lowquality evidence. Agreement: 100\%).

The diagnosis of IBD, according to the WGO practice guideline, encompasses the patient's history, physical examination, laboratory tests, imaging, and endoscopy [4]. The new guideline by the American Society for Gastrointestinal Endoscopy (ASGE), as documented in the 2017 MAYO clinic report [21], recommended chromoendoscopy as the primary surveillance modality based on its better diagnostic yield than random biopsy approaches [5]. The AGA recommends endoscopic evaluation as soon as the diagnosis of IBD is suspected. With particular emphasis on collecting biopsy samples for pathologic evaluation. The AGA focuses more on the pathological findings than on the appearance of the mucosa at first sight [5] compared to the WGO recommendations [4]. MRI has high levels of sensitivity and specificity for diagnosing CD in the small bowel and may be an alternative to endoscopy. It is also helpful in evaluating perianal disease. It is increasingly being used in pediatric patients and young adults due to the lack of radiation exposure and consequent ability to repeat tests safely. Lastly, the CAG guidelines recommend endoscopy and biopsy; however, they suggest using the Crohn's disease activity index (CDAI) [3]. This is useful to determine the initial activity of the disease and the progression over time. In general, when suggestive symptoms of IBD appear, guidelines suggest an endoscopic biopsy approach.

\section{Location and behavior}

The BSG, CAG, WGO, and AGA referenced the Montreal classification of inflammatory bowel disease in their recommendation [1-5]. Classification may help clinicians in patient counseling, disease prognosis, and choice of therapy. The first classification was the Rome classification in 1991; this was later reviewed and changed to the Vienna classification in 1998. Recently, changes have been made to the Vienna version and then the Montreal revision. The Montreal classification takes into consideration the age of diagnosis, location, and behavior [1].

\section{Age}

The Montreal classification allows early onset of the disease, compared to previous versions [1]. This is important since studies have shown that specific serotypes are more common in the early onset of Crohn's disease.

Location

Depends on lesion location when IBD is present, including ileal, colonic, ileocolonic, and isolated upper disease. The most significant change in the Montreal revision was adding upper GIT disease [1]. 
This is considered if the disease is stricturing, penetrating, or neither, and separates the perianal condition since recent studies show that patients with this behavior progress differently. The Montreal revision is also the first one to include a subclassification for UC [1]. This new classification is relevant in recent times.

\section{Activity and severity}

All consulted guidelines agreed that the determination of disease severity should be based on a combination of symptoms, objective measures of inflammation, and factors that predict an increased risk of complications. This includes CDAI, the Ulcerative Colitis Endoscopic Index of Severity (UCEIS), and the Modified Mayo Endoscopic Score. All three of these scores combine findings in endoscopy, symptoms, and inflammation with a recommendation of Grade: strong recommendation in all guidelines.

\section{Management and treatment}

The management and treatment are determined by the severity of the disease, CD vs. UC, location, comorbidities, physical examination, personal tolerance to the treatment, and access to treatment.

\section{Diet}

The BSG guideline recommends that patients with IBD consider what diets meet their specific requirements, and multidisciplinary management with nutritionists is suggested. In patients where nutritional needs cannot be met, enteral or parenteral nutrition is indicated. Patients should be monitored for dietary parameters like hemoglobin, proteins, vitamins, and electrolytes [2]. The CAG guidelines recommend against the use of enteral nutrition to prevent remissions but with a low level of recommendation [3]. The WGO recommends dietary management using nutritionists and monitoring to prevent malnourishment. Unlike CAG, the WGO guidelines also recommend enteral nutrition to prevent remissions [4]. During disease activity, it is appropriate to decrease the amount of fiber. A low residue diet may decrease the frequency of bowel movements. The AGA recommendations are similar to the BSG guidelines; however, it includes an Anti-inflammatory diet for IBD. This diet incorporates four principles: eating probiotics and prebiotics, avoiding lactose, wheat, and refined sugars; combine vegetables and healthy fats in every meal. Due to a lack of available clinical studies to support the claim [5], this has a low recommendation.

\section{Medical treatment}

Oral 5-aminosalicylic acid (5-ASA) is the standard therapy for mild to moderately active IBD. The BSG guideline recommends moderate IBD 5-ASA 2 - 3 g/day with Grade: strong recommendation and highquality evidence. It also recommends the addition of 5-ASA enemas rather than oral treatment alone. The BSG is the only guideline that suggests enemas. The CAG advises against using oral 5-ASA to induce or maintain complete remission in IBD of any severity [3]. The WGO agrees with the BSG guideline, suggesting the use of 5-ASA in oral or rectal forms. In addition, it recommends combining topical and oral treatment to achieve remission and topical therapy to maintain remission. The AGA also recommends the use of 5-ASA in the oral form for control and initial remission. All consulted guidelines agree that corticosteroids are the second level of treatment in patients with low to moderate IBD, where 5-ASA induction therapy fails, except the CAG; their recommendation is to use corticosteroids as the first option. Besides this difference, the guidelines agree on using topically acting oral corticosteroids like budesonide and beclomethasone dipropionate as an option for patients who do not want to experience the side effects of systemic corticosteroids. Patients with moderate to severe IBD should be treated with oral corticosteroids for at least six to eight weeks.

Options for Patients Where 5-ASA Failed

Patients on maintenance therapy with high-dose mesalazine, who required two or more corticosteroid courses in the past year, or who become corticosteroid-dependent or refractory, require treatment escalation with thiopurine, anti-TNF therapy, vedolizumab, or tofacitinib. The choice of drug should be determined by clinical factors, patient choice, cost, likely adherence, and local infusion capacity. This is a consistent statement among revised guidelines with Grade: high.

\section{Surgical management}

Surgery is indicated in patients who have become medically resistant, have intolerable side effects, or presents with life-threatening conditions. Surgery should be considered an alternative to medical treatment early in the disease course for short-segment CD limited to the distal ileum [22]. The level of the guidelines' recommendation was "High" and all agreed that IBD patients will need surgery at some point in their lives to relieve symptoms if treatment fails or to correct complications. Surgery performed by a specialist can be curative for the affected areas but is considered an alternative treatment. The suggested procedures are total proctocolectomy (plus permanent ileostomy), ileal pouch-anal anastomosis, and segmental resection (mainly in elderly patients) [23]. 


\section{Cureus}

\section{Alternative treatments}

Treatments like fecal microbial transplantation, marijuana, probiotics, and prebiotics are only mentioned by the BSG and WGO, with a high level of evidence that encourages their use [2, 4]. The CAG and AGA recommend alternative therapies on $\operatorname{IBD}[3,5]$.

\section{Resveratrol}

Recent works of literature have shown that resveratrol, found in peanuts, grapes, and red wine, may be helpful [24]. Several studies have expounded on its anti-inflammatory and antioxidant properties to prove its linkage to the improvement of dextran sodium sulfate (DSS)-induced colitis, IL-10-/- chronic colitis in mice, and resveratrol-induced immunosuppressive CD11b+Gr-1+ cells that express ARG-1, which correlated with reversal of chronic colitis severity [25].

\section{Pomegranate}

Studies suggest that the ellagic acid-rich fractions and metabolites of pomegranate urolithin-A provide a protective effect against colitis [26].

Bromelain

Bromelain, which can be gotten from pineapples, has also ameliorated immune-mediated disease properties, including IBD [27]. Further studies on colon biopsies of human IBD patients with bromelain show a decrease in the production of proinflammatory cytokines and chemokines, which suggests a direct effect at effector sites [25, 27-28].

\begin{tabular}{|c|c|c|c|c|}
\hline Category & BSG & CAG & WGO & AGA \\
\hline Diagnosis & $\begin{array}{l}\text { Recommends ileocolonoscopy, } \\
\text { including segmental colonic and } \\
\text { ileal biopsies, if small bowel } \\
\text { disease is suspected; follow-up } \\
\text { with CT enterography. }\end{array}$ & $\begin{array}{l}\text { Recommends endoscopy and } \\
\text { biopsy, using the Crohn's } \\
\text { Disease Activity Index (CDAl) as } \\
\text { a predictor }\end{array}$ & $\begin{array}{l}\text { Recommends colonoscopy } \\
\text { and sigmoidoscopy for the } \\
\text { diagnosis using the Mayo } \\
\text { endoscopic score and the } \\
\text { Ulcerative Colitis Endoscopic } \\
\text { Index of Severity (UCEIS) } \\
\text { score }\end{array}$ & $\begin{array}{l}\text { Recommends endoscopic } \\
\text { evaluation. Special emphasis } \\
\text { on pathology evaluation. }\end{array}$ \\
\hline $\begin{array}{l}\text { Location } \\
\text { and } \\
\text { behavior }\end{array}$ & Used the Montreal classification & Used the Montreal classification & $\begin{array}{l}\text { Used the Montreal } \\
\text { classification }\end{array}$ & $\begin{array}{l}\text { Used the Montreal } \\
\text { classification }\end{array}$ \\
\hline $\begin{array}{l}\text { Severity } \\
\text { Grading }\end{array}$ & $\begin{array}{l}\text { They recommended that disease } \\
\text { severity should be based on a } \\
\text { combination of symptoms and } \\
\text { objective measures of } \\
\text { inflammation. They further } \\
\text { recommended using Crohn's } \\
\text { Disease Activity Index (CDAI), the } \\
\text { Ulcerative Colitis Endoscopic } \\
\text { Index of Severity (UCEIS), and the } \\
\text { modified Mayo endoscopic score. }\end{array}$ & $\begin{array}{l}\text { They recommended that } \\
\text { disease severity should be } \\
\text { based on a combination of } \\
\text { symptoms and objective } \\
\text { measures of inflammation. They } \\
\text { further recommended using } \\
\text { Crohn's Disease Activity Index } \\
\text { (CDAI), the Ulcerative Colitis } \\
\text { Endoscopic Index of Severity } \\
\text { (UCEIS), and the modified Mayo } \\
\text { endoscopic score. }\end{array}$ & $\begin{array}{l}\text { They recommended that } \\
\text { disease severity should be } \\
\text { based on a combination of } \\
\text { symptoms and objective } \\
\text { measures of inflammation. } \\
\text { They further recommended } \\
\text { using Crohn's Disease } \\
\text { Activity Index (CDAI), the } \\
\text { Ulcerative Colitis Endoscopic } \\
\text { Index of Severity (UCEIS), } \\
\text { and the modified Mayo } \\
\text { endoscopic score. }\end{array}$ & $\begin{array}{l}\text { They recommended that } \\
\text { disease severity should be } \\
\text { based on a combination of } \\
\text { symptoms and objective } \\
\text { measures of inflammation. } \\
\text { They further recommended } \\
\text { using Crohn's Disease } \\
\text { Activity Index (CDAl), the } \\
\text { Ulcerative Colitis Endoscopic } \\
\text { Index of Severity (UCEIS), } \\
\text { and the modified Mayo } \\
\text { endoscopic score. }\end{array}$ \\
\hline \multirow[t]{2}{*}{$\begin{array}{l}\text { Dietary } \\
\text { changes }\end{array}$} & $\begin{array}{l}\text { Diet should meet nutritional } \\
\text { requirements. Multidisciplinary } \\
\text { management with nutritionists. In } \\
\text { patients where nutritional } \\
\text { requirements cannot be met, } \\
\text { enteral or parenteral nutrition is } \\
\text { indicated. Patients should be } \\
\text { monitored for nutritional } \\
\text { parameters, including } \\
\text { hemoglobin, proteins, vitamins, } \\
\text { and electrolytes. }\end{array}$ & $\begin{array}{l}\text { Recommends against the use } \\
\text { of enteral nutrition to prevent } \\
\text { remissions, but with a low level } \\
\text { of recommendation. }\end{array}$ & $\begin{array}{l}\text { Dietary management with the } \\
\text { aid of nutritionists and } \\
\text { monitoring to prevent } \\
\text { malnourishment. } \\
\text { Recommended use of enteral } \\
\text { nutrition to prevent } \\
\text { remissions. }\end{array}$ & $\begin{array}{l}\text { An anti-inflammatory diet } \\
\text { with probiotics and } \\
\text { prebiotics, avoid lactose, } \\
\text { wheat, and refined sugars; } \\
\text { combine vegetables and } \\
\text { healthy fats in every meal. }\end{array}$ \\
\hline & $\begin{array}{l}\text { They recommended 5-ASA. For } \\
\text { moderate IBD, they }\end{array}$ & $\begin{array}{l}\text { They recommended 5-ASA for } \\
\text { any IBD severity and using oral }\end{array}$ & $\begin{array}{l}\text { They recommended 5-ASA } \\
\text { orally, combined with rectal }\end{array}$ & $\begin{array}{l}\text { They recommended 5-ASA } \\
\text { orally, combined with rectal }\end{array}$ \\
\hline
\end{tabular}


Henry Elukeme - APC drive, methodology, project administration, resources, oversight, and leadership

Imoh L. Ebong - Validation, visualization, writing - original draft, writing - review and editing, and leadership.

Olamide O. Ajayi - Conceptualization, validation, visualization, writing - original draft, visualization, writing - initial draft,

Iyanu V. Olateju - Visualization, writing - original draft, resources, software, validation

Anthonette Taiwo - Investigation, methodology, project administration, writing - original draft, writing review and editing

Ifeoma C. Anaya - Conceptualization, validation, visualization, sriting - original draft.

Janet A. Omole - Methodology, project administration, resources, data curation

Mireille B. Nkongho - Writing of the article, reviewing and/or revising the text and/or figures

Ugochi Ojinnaka - Writing of the article, reviewing and/or revising the text, visualization

Abimbola O. Ajibowo - Project administration, drafting or revising the article, resources

Omosefe E. Ogbeifun - Validation, visualization, drafting, or revising the article

Osemwegie O. Ugbo - Drafting or revising the article, writing - review and editing

Ovie Okorare - Editing, writing, and review of the original draft

Zainab Akinsola - Editing, concept rephrasing, and maintenance of research data integrity

Rahman A. Olusoji - Literature search, writing, and editing

Ijeoma O. Amanze - Preparation, typing, literature search, and editing

Jane N. Nwafor - Formal analysis of methodology, writing, and drafting of conclusion

Nnenna A. Ukoha - Drafting or revising the article, writing - review and editing

Thomas A. Elimihele - Project administration, writing - original draft, writing - review and editing

\section{Additional Information \\ Disclosures}

Conflicts of interest: In compliance with the ICMJE uniform disclosure form, all authors declare the following: Payment/services info: All authors have declared that no financial support was received from any organization for the submitted work. Financial relationships: All authors have declared that they have no financial relationships at present or within the previous three years with any organizations that might have an interest in the submitted work. Other relationships: All authors have declared that there are no other relationships or activities that could appear to have influenced the submitted work.

\section{Acknowledgements}

This paper and the research behind it would not have been possible without the exceptional support of the team of fellow researchers who put in relentless efforts to make this manuscript possible. I am also grateful for the insightful comments offered by the anonymous peer reviewers who reviewed this article. The generosity and expertise of one and all have improved this study in innumerable ways and saved me from many errors; those that inevitably remain are entirely my responsibility. It is with genuine pleasure that I acknowledge the contributions of my amazing life partner and wife - Rita Kimble Okobi (with my three precious kids -Ethan, Eliana, and Eliora), who has given up many evenings to read and edit every aspect of this paper in combination with compassionate criticism that only a loving wife could muster for what she fondly calls "my obsession with details."

\section{References}

1. Satsangi J, Silverberg MS, Vermeire S, Colombel J: The Montreal classification of inflammatory bowel 
disease: controversies, consensus, and implications. Gut. 2006, 55:749-53. 10.1136/gut.2005.082909

2. Lamb C, Kennedy N, Raines T, et al.: British Society of Gastroenterology consensus guidelines on the management of inflammatory bowel disease in adults. Gut. 2019, 68:s1-s106. 10.1136/gutjnl-2019-318484

3. Panaccione R, Steinhart H, Bressler B, et al.: Canadian Association of Gastroenterology clinical practice guideline for the management of luminal Crohn's disease. J Can Assoc Gastroenterol. 2019, 2:e1-e34. 10.1093/jcag/gwz019

4. Bernstein CN, Eliakim A, Fedail S, et al.: World Gastroenterology Organisation Global Guidelines. Inflammatory bowel disease: update August 2015. J Clin Gastroenterol. 2016, 50:803-18. 10.1097/MCG.0000000000000660

5. Farraye FA, Odze RD, Eaden J, Itzkowitz SH: AGA technical review on the diagnosis and management of colorectal neoplasia in inflammatory bowel disease. Gastroenterology. 2010, 138:746-74. 10.1053/j.gastro.2009.12.035

6. Shapiro JM, Subedi S, LeLeiko NS: Inflammatory bowel disease. Pediatr Rev. 2016, 37:337-47. 10.1542/pir.2015-0110

7. Data and Statistics: Inflammatory Bowel Disease Prevalence (IBD) in the United States . (2021). Accessed: July 14, 2021: http://www.cdc.gov/ibd/data-statistics.htm.

8. Data and Statistics: Inflammatory Bowel Disease (IBD) in the United States . (2020). Accessed: July 25, 2021: http://www.cdc.gov/ibd/data-statistics.htm\#2.

9. The Facts About Inflammatory Bowel Disease. (2020). Accessed: July 25, 2021: http://www.crohnscolitisfoundation.org/sites/default/files/2019-02/Updated\%20IBD\%20Factbook.pdf.

10. Flynn S, Eisenstein S: Inflammatory bowel disease presentation and diagnosis. Surg Clin North Am. 2019, 99:1051-62. 10.1016/j.suc.2019.08.001

11. Wehkamp J, Götz M, Herrlinger K, Steurer W, Stange EF: Inflammatory bowel disease: Crohn's disease and ulcerative colitis. Dtsch Arztebl Int. 2016, 113:72-82. 10.3238/arztebl.2016.0072

12. Rosenstiel P, Sina C, Franke A, Schreiber S: Towards a molecular risk map--recent advances on the etiology of inflammatory bowel disease. Semin Immunol. 2009, 21:334-45. 10.1016/j.smim.2009.10.001

13. Zhang YZ, Li YY: Inflammatory bowel disease: pathogenesis. World J Gastroenterol. 2014, 20:91-99. 10.3748/wig.v20.i1.91

14. Cosnes J: Smoking, physical activity, nutrition and lifestyle: environmental factors and their impact on IBD . Dig Dis. 2010, 28:411-17. 10.1159/000320395

15. Leslie WD, Miller N, Rogala L, Bernstein CN: Vitamin D status and bone density in recently diagnosed inflammatory bowel disease: the Manitoba IBD Cohort Study. Am J Gastroenterol. 2008, 103:1451-59. 10.1111/j.1572-0241.2007.01753.x

16. Halfvarson J, Brislawn CJ, Lamendella R, et al.: Dynamics of the human gut microbiome in inflammatory bowel disease. Nat Microbiol. 2017, 2:17004. 10.1038/nmicrobiol.2017.4

17. Sairenji T, Collins KL, Evans DV: An update on inflammatory bowel disease . Prim Care. 2017, 44:673-92. 10.1016/j.pop.2017.07.010

18. Zheng L, Wen X: Gut microbiota and inflammatory bowel disease: the current status and perspectives . World J Clin Cases. 2021, 9:321-33. 10.12998/wjcc.v9.i2.321

19. Jantchou P, Morois S, Clavel-Chapelon F, Boutron-Ruault MC, Carbonnel F: Animal protein intake and risk of inflammatory bowel disease: the E3N prospective study. Am J Gastroenterol. 2010, 105:2195-201. 10.1038/ajg.2010.192

20. Seyedian SS, Nokhostin F, Malamir MD: A review of the diagnosis, prevention, and treatment methods of inflammatory bowel disease. J Med Life. 2019, 12:113-22. 10.25122/jml-2018-0075

21. Chromoendoscopy better than random biopsies for IBD surveillance, but... . (2017). Accessed: 07/25/2021: http://www.mayoclinic.org/medical-professionals/digestive-diseases/news/chromoendoscopy-better-thanrandom-biopsies-f....

22. Mayberry JF, Lobo A, Ford AC, Thomas A: NICE clinical guideline (CG152): the management of Crohn's disease in adults, children and young people. Aliment Pharmacol Ther. 2013, 37:195-203. 10.1111/apt.12102

23. Matsuoka K, Kobayashi T, Ueno F, et al.: Evidence-based clinical practice guidelines for inflammatory bowel disease. J Gastroenterol. 2018, 53:305-53. 10.1007/s00535-018-1439-1

24. Nunes S, Danesi F, Del Rio D, Silva P: Resveratrol and inflammatory bowel disease: the evidence so far . Nutr Res Rev. 2018, 31:85-97. 10.1017/S095442241700021X

25. Singh UP, Singh NP, Busbee B, et al.: Alternative medicines as emerging therapies for inflammatory bowel diseases. Int Rev Immunol. 2012, 31:66-84. 10.3109/08830185.2011.642909

26. Singh K, Jaggi AS, Singh N: Exploring the ameliorative potential of Punica granatum in dextran sulfate sodium induced ulcerative colitis in mice. Phytother Res. 2009, 23:1565-74. 10.1002/ptr.2822

27. Hale LP, Greer PK, Trinh CT, Gottfried MR: Treatment with oral bromelain decreases colonic inflammation in the IL-10-deficient murine model of inflammatory bowel disease. Clin Immunol. 2005, 116:135-42. 10.1016/j.clim.2005.04.011

28. Kane S, Goldberg MJ: Use of bromelain for mild ulcerative colitis . Ann Intern Med. 2000, 132:680. 10.7326/0003-4819-132-8-200004180-00026 